\title{
Transgenitalização masculino / feminino: experiência do Hospital Universitário da UFRJ
}

\section{Male-to-female transsexual surgery: experience at the UFRJ University Hospital}

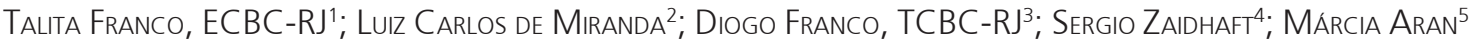

\author{
R E S U M O
}

\begin{abstract}
Objetivo: Mostrar a experiência do tratamento cirúrgico do transgenitalismo (masculino/feminino) realizado no Programa de Transgenitalização do Hospital Universitário Clementino Fraga Filho, - UFRJ. Métodos: A seleção dos pacientes para operação de transgenitalismo obedeceu à avaliação de equipe multidisciplinar, atendendo aos critérios definidos, após dois anos de acompanhamento conjunto: diagnóstico médico de transexualismo; paciente maior de 21 anos; ausência de características físicas inapropriadas para a mudança; apoio de pelo menos um familiar próximo. Resultados: De 1997 a 2004 foram atendidas dezessete, pessoas quinze confirmaram a condição transexual, uma foi afastada por ter trazido exames falsos. Do total de dezesseis transexuais, foram realizadas seis operações. As pacientes operadas situavam-se na faixa de 25 a 40 anos com média de 31 anos. 0 procedimento cirúrgico foi concluído sem dificuldades técnicas em todas as pacientes. Uma paciente apresentou estenose do neo meato e em outra foi necessário encurtar um pouco mais a uretra. Conclusão: A técnica operatória não oferece maiores dificuldades em sua execução, mas pode depender das condições locais e da criatividade do cirurgião. A dificuldade maior está em preparar estes pacientes para que não haja frustrações ou expectativas demasiadas.
\end{abstract}

Descritores: Transexualismo/cirurgia. Transexualismo/diagnóstico.

\section{INTRODUÇÃO}

A s operações para a transgenitalização tiveram o seu início histórico em 1970, quando Edgerton ${ }^{1}$ publicou sua técnica que utilizava os tecidos do pênis e da bolsa escrotal para configurar uma genitália externa feminina aproveitando, inclusive, a glande para simular um colo de útero. O inconveniente maior era a necessidade de dois tempos cirúrgicos.

No Brasil, as primeiras operações para mudança de sexo foram realizadas por Roberto Farina, e publicadas em 1975 com o seguinte título: "Transexualismo: do homem à mulher normal através dos estados de intersexualidade e das parafilias" 2 , apresentando resultados muito interessantes.

Em 1997, o Conselho Federal de Medicina, após um importante debate, publicou a Resolução $n^{\circ} 1482 / 97^{3}$ que autorizava, a título experimental, em hospitais universitários, a realização de neocolpovulvoplastia, neofaloplastia e/ou procedimentos complementares sobre gônadas e caracteres sexuais secundários como tratamento dos casos de transexualismo. Cinco anos após, nova Resolução de $n^{\circ}$ 1652/2002 ${ }^{4}$, passou a autorizar a realização de cirurgia de transgenitalização masculino / feminino em hospitais públicos ou privados desde que seguissem um programa rígido de seleção realizado por uma equipe multidisciplinar. A versão feminino / masculino persiste reservada aos hospitais universitários.

O parecer sobre estas operações considerou-as de acordo com princípios da Bioética quais sejam, o princípio da beneficência, pois buscam a integração entre o corpo e a identidade sexual psíquica do interessado e os princípios de autonomia e justiça, contemplando o direito de autodeterminação em dispor do próprio corpo e evitando a discriminação no pleito à operação, já acessível à população das classes média e alta. Neste sentido, o Conselho Federal de Medicina definiu como terapêutica a correção cirúrgica da genitália externa e dos caracteres sexuais secundários no caso de diagnóstico de transexualismo.

Tendo em vista tais resoluções e a demanda já existente em nosso meio pela realização de tais procedimentos, optamos no ano de 1997 pelo início de um pro-

Trabalho realizado no Hospital Universitário Clementino Fraga Filho da Universidade Federal do Rio de Janeiro (HUCFF - UFRJ); Trabalho agraciado com o Prêmio Ivo Pitanguy, como melhor artigo científico apresentado durante o $44^{\circ}$ Congresso Brasileiro de Cirurgia Plástica, novembro de 2007.

1. Professora Titular da UFRJ; Chefe do Serviço de Cirurgia Plástica do HUCFF- Rio de Janeiro- RJ-BR; 2. Professor Adjunto da UFRJ; Membro do Serviço de Urologia do HUCFF- Rio de Janeiro- RJ-BR; 3. Professor Adjunto da UFRJ; Membro do Serviço de Cirurgia Plástica do HUCFF- Rio de Janeiro- RJ-BR; 4. Professor Assistente de Psiquiatria e Medicina Legal da UFRJ- Rio de Janeiro- RJ-BR; 5. Psicóloga do Serviço de Psicologia e Saúde Mental do HUCFF da UFRJ- Rio de Janeiro- RJ-BR. 
grama de transgenitalização. Objetivamos com esse trabaIho retrospectivo descrever a nossa experiência com esse tipo de tratamento cirúrgico.

\section{MÉTODOS}

Segundo nosso protocolo, a definição de transexualismo obedece, no mínimo, aos seguintes critérios: desconforto com o sexo anatômico natural; desejo expresso de eliminar os genitais, perder as características primárias e secundárias do próprio sexo e ganhar as do sexo oposto; permanência desses distúrbios de forma contínua e consistente por, no mínimo, dois anos; ausência de outros transtornos mentais. Esta definição é semelhante à proposta, em 2000, pela American Psychiatric Association ${ }^{5}$

A seleção dos pacientes para operação de transgenitalismo obedeceu à avaliação de equipe multidisciplinar, atendendo aos critérios definidos, após dois anos de acompanhamento conjunto: diagnóstico médico de transexualismo; paciente maior de 21 anos; ausência de características físicas inapropriadas para a mudança; apoio de pelo menos um familiar próximo

Tendo em vista a complexidade e a irreversibilidade destes procedimentos, vários especialistas estão envolvidos, entre os quais psiquiatras, assistentes sociais, endocrinologistas, geneticistas, urologistas e cirurgiões plásticos. Para que fossem admitidos no Programa de Transgenitalização os pacientes deveriam seguir as etapas citadas na tabela 1.

\section{Técnica operatória}

Os pacientes foram internados na véspera da operação realizando-se o preparo de cólon. As operações foram realizadas sob anestesia geral ou peridural. O cateterismo vesical de demora foi realizado logo após a anestesia.
O ato cirúrgico é iniciado com a delimitação de um retalho perineal, de base posterior, situada na projeção das tuberosidades isquiáticas. Este retalho é descolado no plano fascial e é protegido durante as manobras de ressecção. A bolsa escrotal é esvaziada retirando-se os testículos, porém conservando-se os cordões espermáticos e seus envoltórios que são de utilidade para dar consistência aos futuros grandes lábios. Uma incisão circular é feita no contorno da glande e a pele peniana é descolada em toda sua extensão, permitindo a exteriorização dos corpos cavernosos e esponjoso que permanece cateterizado. Os corpos cavernosos são dissecados e amputados, conservando-se pequenos segmentos que serão suturados entre si e à aponeurose pubiana, para simular o clitóris (Figuras 1A, 1B, 1C, 1D e 1E).

Para criar o "túnel vaginal", utiliza-se a técnica de acesso à próstata pela via perineal descrita por Young ${ }^{6}$ (1905) e modificada por Belt ${ }^{7}$ (1942). O acesso à fossa ísquioretal é feito por dissecção digital, bilateral, seguida de incisão do tendão central, preservando as estruturas do esfíncter externo do ânus. A dissecção progride na direção da próstata, mantendo a parede do reto rebatida para baixo. Podese aprofundar a cavidade cortando o músculo reto-ureteral e ainda, se necessário, abrindo a fáscia posterior de Denonvillier para atingir o plano próximo às vesículas seminais, abaixo da próstata. Este tempo cirúrgico exige cuidado, pois, além do sangramento abundante, há o risco de lesão retal (Figuras 2A e 2B).

Dois pontos com fio de mononylon 3-0 são dados, um a cada lado da próstata, no fundo deste túnel, e são deixados reparados para uso posterior na fixação da neo-vagina.

O envoltório peniano vazio é incisado longitudinalmente em sua face ventral, obtendo-se um retalho retangular de base superior que será suturado ao retalho perineal de base posterior, preparado no início da operação. Na base do retalho peniano, é feito um pequeno orifício que dará passagem ao corpo esponjoso contendo

Tabela 1 - Rotina do Atendimento Interdisciplinar.

\section{Triagem}

Demanda espontânea ou referida para cirurgia de transgenitalização

Avaliação Psiquiátrica no ambulatório de Saúde Mental

Entrevista para avaliação e esclarecimento do funcionamento do Programa de acordo com os critérios do Conselho Federal de Medicina

Abertura do Prontuário

Entrevista com o Serviço Social

Avaliação pela Endocrinologia

Encaminhamento para Psicoterapia no Ambulatório de Saúde Mental

Avaliação pela Urologia

Avaliação pela Cirurgia Plástica

Concordância e assinatura no Termo de Consentimento Livre e Esclarecido

Realização da cirurgia de transgenitalização

Acompanhamento pós-operatório de, pelo menos, seis meses 


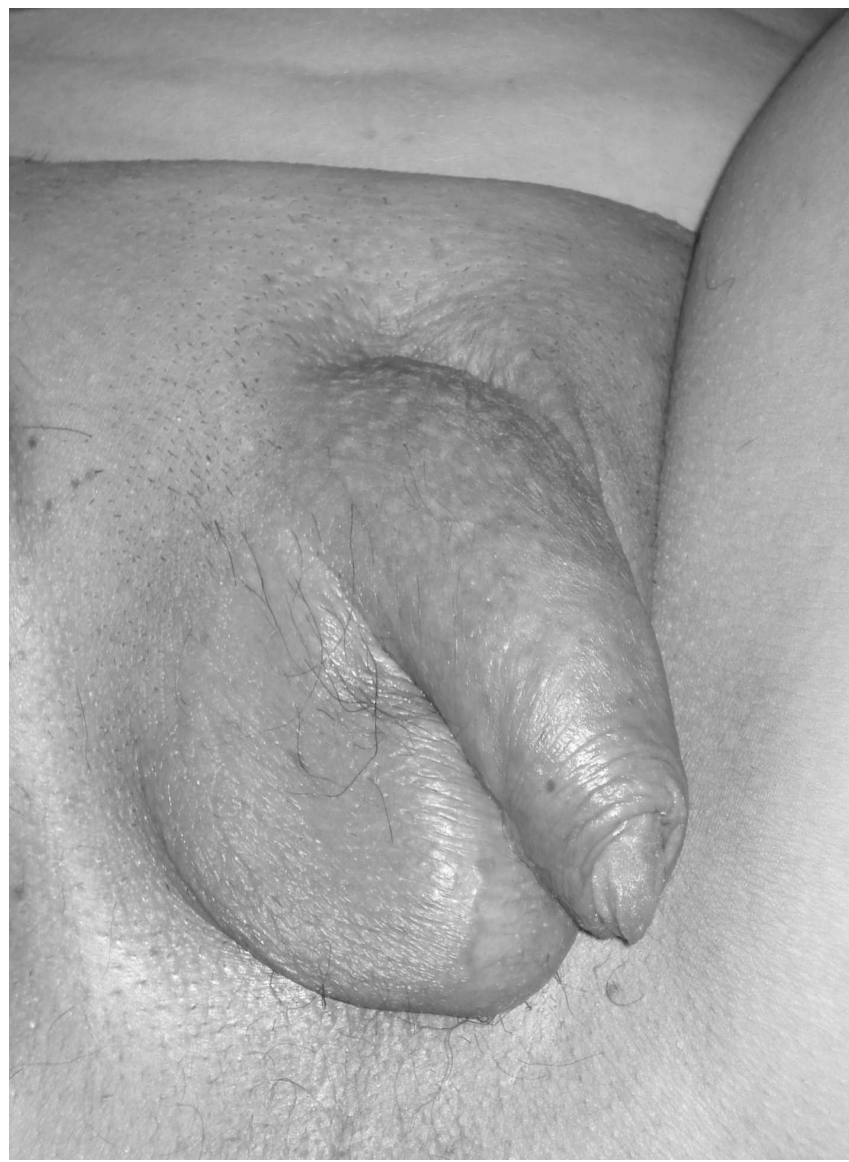

Figura 1-A - Pré-operatório de transgenitalização.

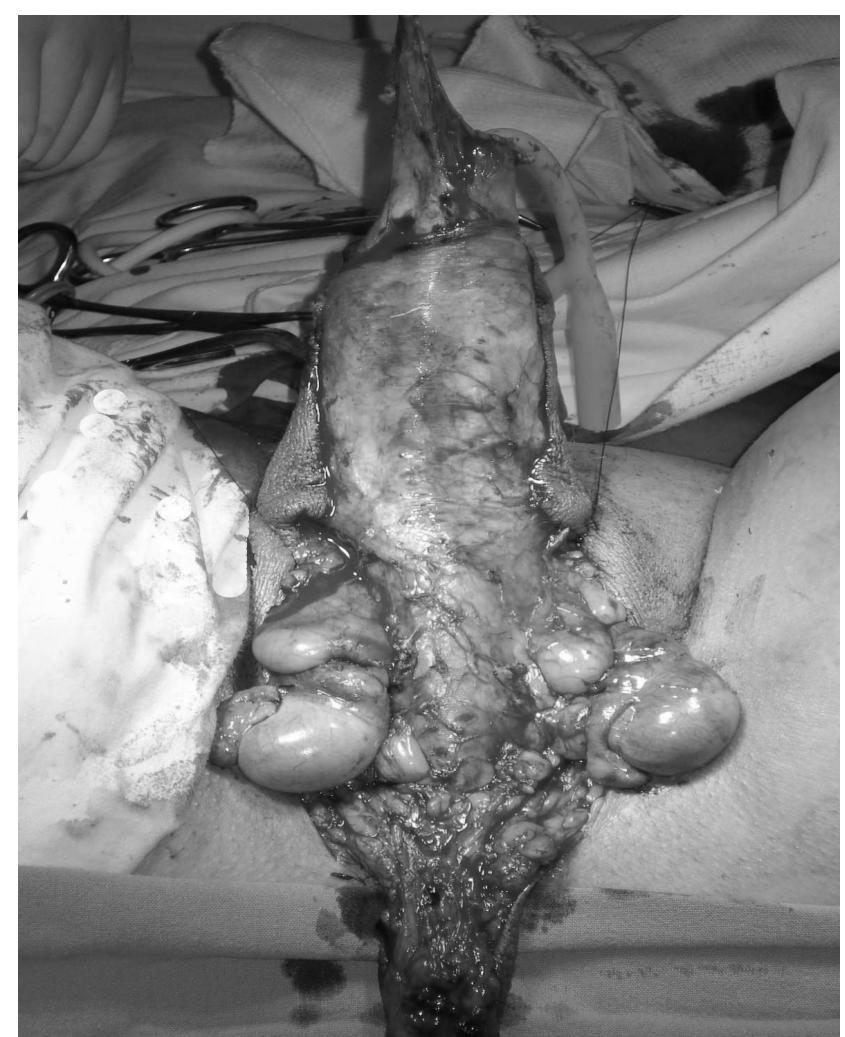

Figura 1-C - Exposição dos testículos e dos corpos cavernosos esponjoso, antes da ressecção.

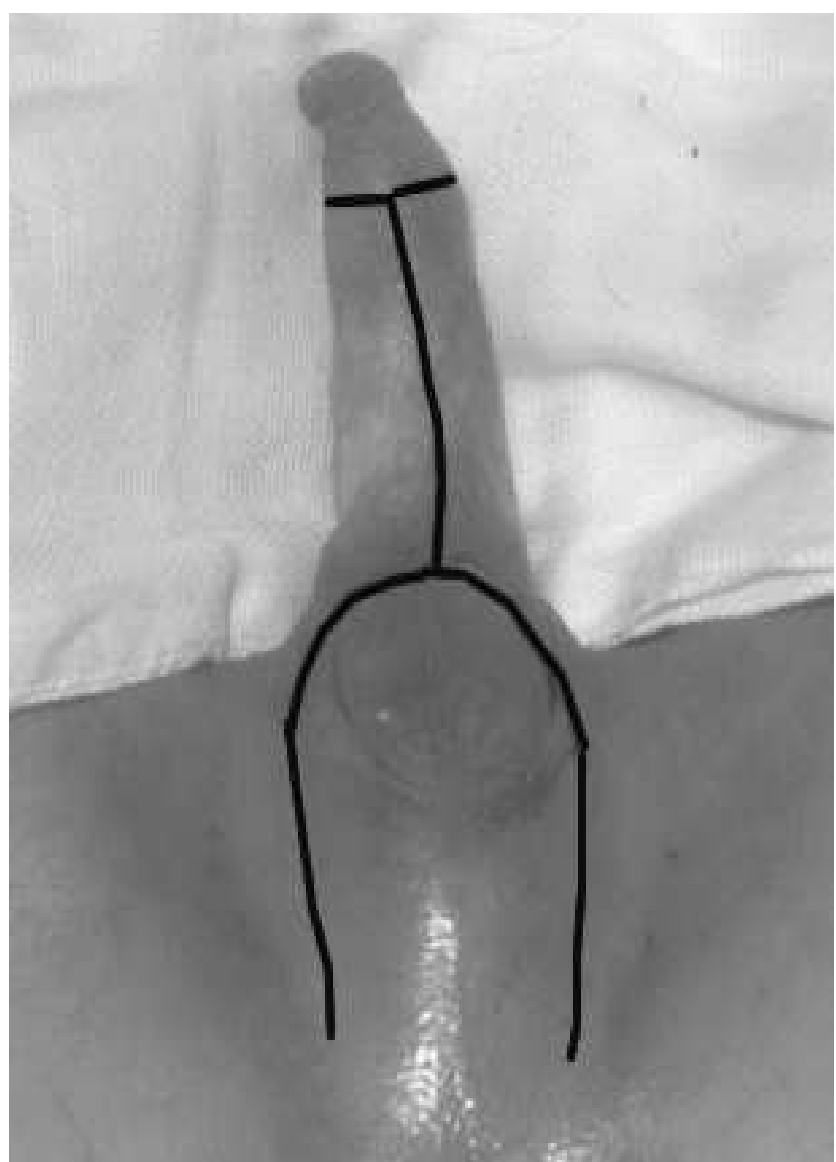

Figura 1-B - Marcação dos retalhos.

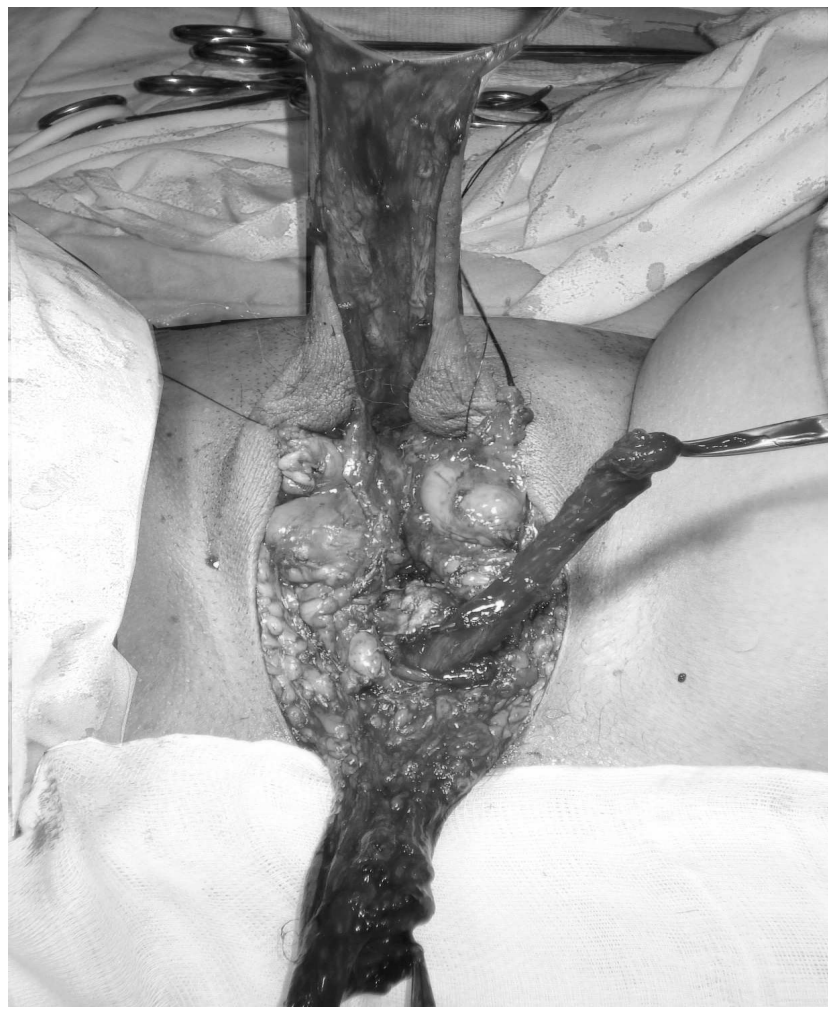

Figura 1-D - Testículos e corpos cavernosos já ressecados, vendo-se a uretra reparada e os retalhos anterior e posterior que, após serem suturados entre si, formarão a neovagina. 


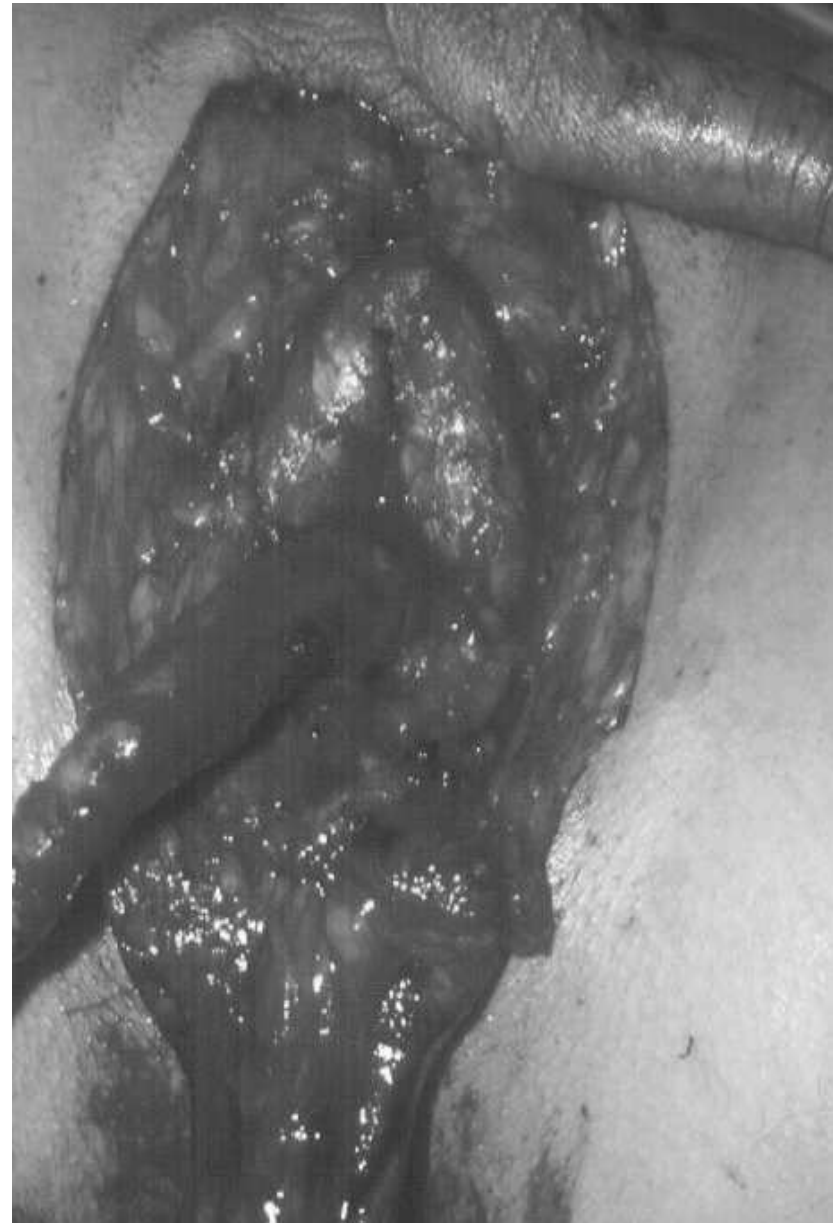

Figura 1-E - Pequenos segmentos dos corpos cavernosos são preservados e fixados na aponeurose pubiana para simular um clitóris.

a uretra que ainda não foi encurtada. O cilindro cutâneo resultante destes retalhos suturados é invertido e sua extremidade introduzida no túnel dissecado no espaço retovesical. Os pontos de mononylon 3-0 fixados no fundo do túnel transfixarão a extremidade do retalho invertido garantindo sua aderência e a persistência da profundidade desta neo-vagina. O encurtamento da uretra é feito sob discreta tensão de forma a deprimir a parte central da base do retalho superior o que fará as partes moles em seu contorno simularem pequenos lábios. A pele da bolsa escrotal é modelada de forma a reproduzir os grandes lábios que serão preenchidos com os tecidos dos cordões espermáticos. Um ponto captonado dado na linha média, na extremidade superior da neo-vulva, aproximando os tecidos profundos contribui para formar a comissura anterior. Ao final do procedimento cirúrgico será colocado molde de espuma de borracha revestido por preservativo. O edema local costuma ser acentuado na primeira semana, (Figuras $3 A, 3 B, 3 C, 3 D$ e $3 E$ ). A sonda vesical é mantida até o sétimo dia de pós-operatório e o molde deve ser usado durante pelo menos dois meses. As relações sexuais vaginais estão liberadas a partir deste período.

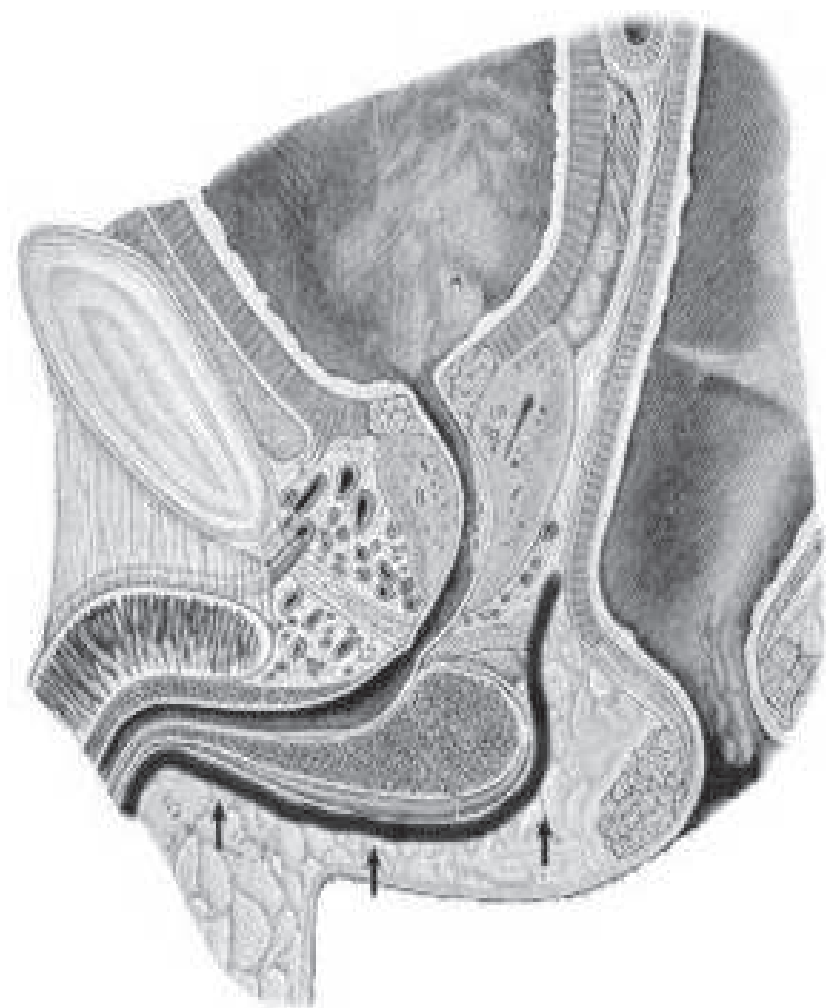

Figura 2-A - Corte sagital mostrando o trajeto descrito pela dissecção para confecção da loja.

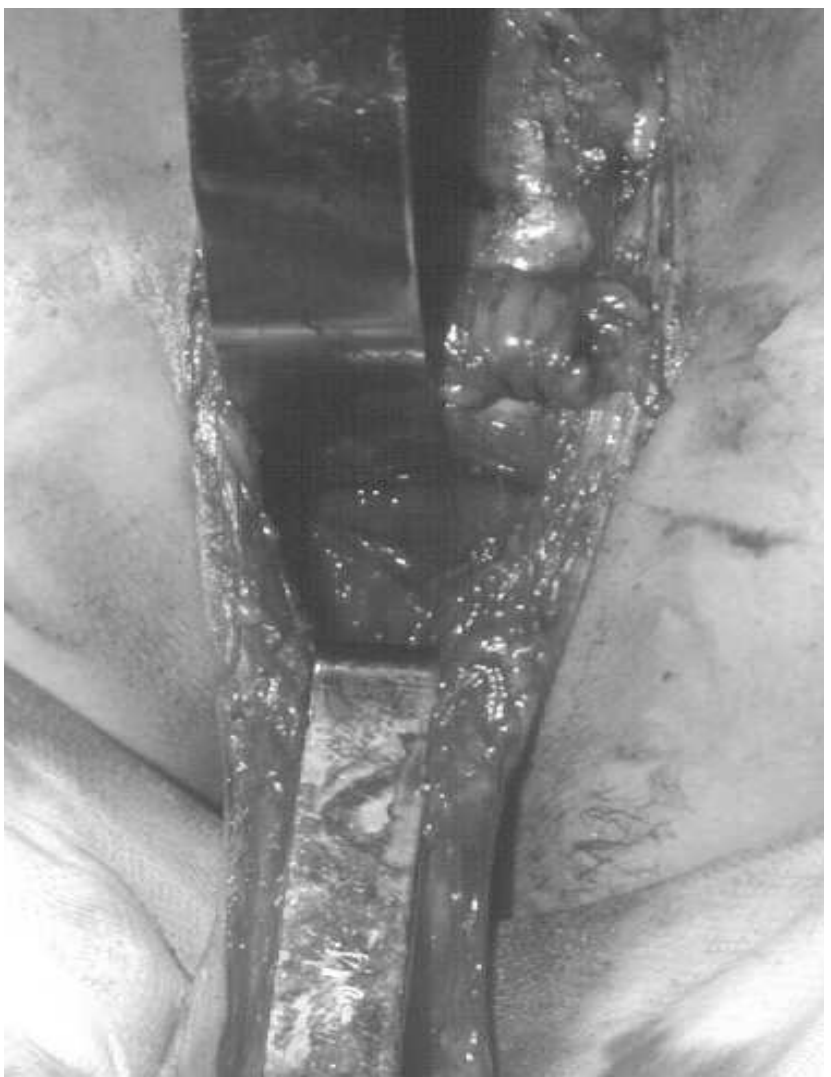

Figura 2-B - Visibilização do amplo túnel preparado. 


\section{RESULTADOS}

De 1997 a 2004 foram atendidas dezessete pessoas, encaminhadas por outros Serviços do próprio Hospital (Clínica Médica, Endocrinologia e Urologia) ou indicadas por pacientes que já se encontravam em atendimento. Destas, quinze confirmaram a condição transexual, e uma, que foi encaminhada com a hipótese de hermafroditismo, foi afastada por ter trazido exames falsos. Do total de dezesseis transexuais, foram realizadas seis operações, houve uma desistência, três abandonos, uma recusa de inclusão no programa por ser menor de idade, uma veio ao Programa já operada em outro país (visando laudo psiquiátrico para troca de nome), e quatro pacientes encontram-se na fila de espera. As pacientes operadas situavam-se na faixa de 25 a 40 anos com média de 31 anos.

O procedimento cirúrgico pode ser concluído, com sucesso e sem dificuldades técnicas em todas as pacientes. O resultado estético foi considerado excelente por todas elas, que se mostraram muito satisfeitas não só com a ablação da genitália masculina, mas também com o aspecto estético na nova genitália (Figuras 4A e 4B e 5A e 5B). Em um paciente foi necessário encurtar um pouco mais a uretra que ainda fazia protrusão entre os grandes lábios.

Houve necessidade de reposição volêmica em um paciente, por perda sanguinea transoperatória no tempo cirúrgico da amputação dos corpos cavernosos, este paciente já apresentava hemoglobina baixa no pré operatório.

Uma paciente apresentou, no sétimo dia pósoperatório, deiscência traumática do retalho posterior da neo-vagina que foi novamente suturado e a paciente evoluiu bem. O trauma foi decorrente de manobras intempestivas feitas durante troca do molde. Uma paciente apresentou estenose do neo meato uretral e foi submetida à meatotomia para a correção da estenose.

\section{DISCUSSÃO}

O termo Transexual foi usado inicialmente por Harry Benjamin², em 1953, que analisou vários aspectos da sexualidade e concluiu que "o homossexual tem um problema sexual, o travesti tem um problema social e o transexual tem um problema de gênero". Com a aceitação cada vez maior do direito de cada um por sua opção sexual os três "problemas" mencionados por Harry Benjamin talvez se restrinjam, futuramente, apenas ao terceiro. Levará ainda algum tempo para que este tipo de procedimento seja visto com naturalidade, sobretudo por ser radical e irreversível. Por um lado, é bom que seja assim. Tal decisão exige tempo e acompanhamento especializado para que o bom resultado cirúrgico seja apenas parte de um processo de reestruturação geral da pessoa com final feliz. A autorização do $\mathrm{CFM}^{4}$ para que esta operação pos- sa ser feita em clínicas particulares poderá acarretar problemas futuros se não forem seguidas as etapas preconizadas antes da cirurgia de transgenitalização, sobretudo o acompanhamento psicológico durante dois anos. É preciso, também, que os aspectos legais se tornem mais ágeis, pois a mudança oficial da documentação é difícil e complicada levando a situações constrangedoras e prejuízos financeiros.

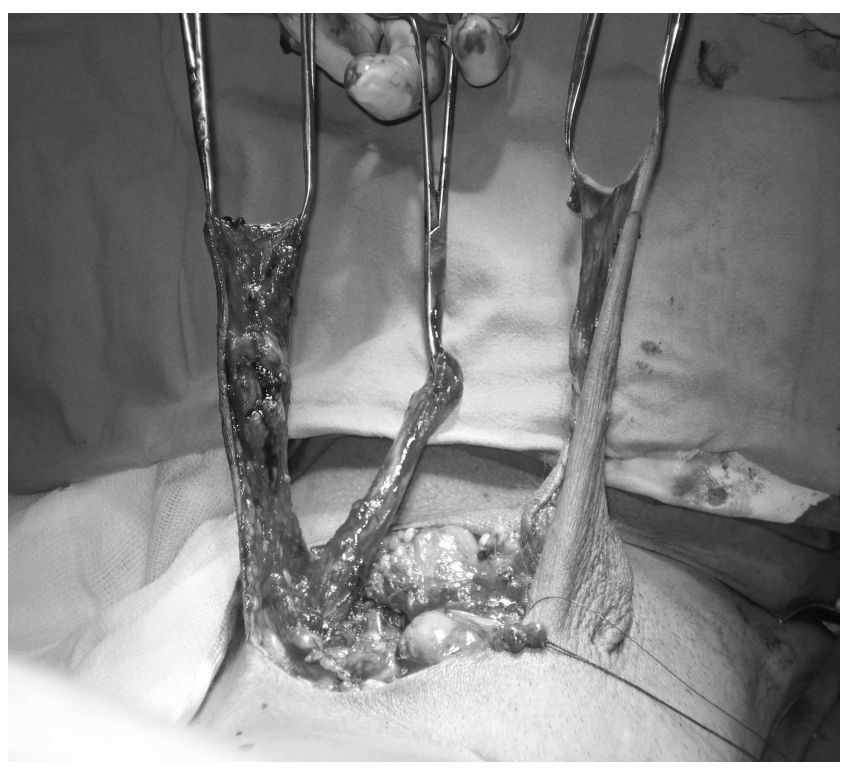

Figura 3-A - Terminada a ressecção, vê-se o retalho peniano, à direita, o retalho perineal à esquerda e a uretra no meio.

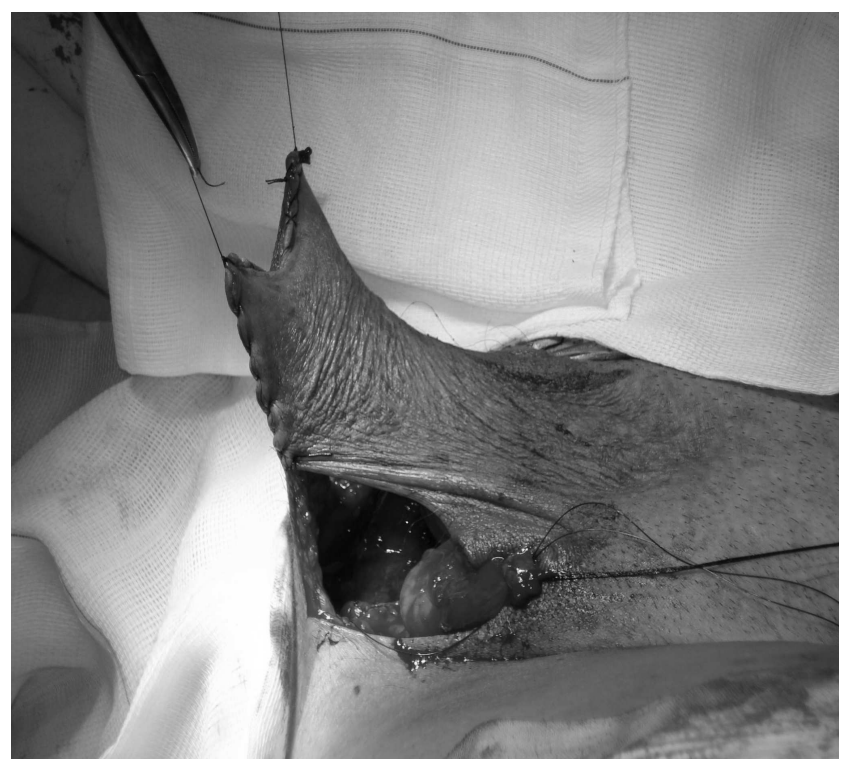

Figura 3-B - O retalho peniano é suturado ao retalho perineal formando um tubo fechado na extremidade, o qual será invertido e introduzido no espaço vésicoretal para revestir suas paredes. A uretra está reparada, aguardando a confecção de um pertuito na base do retalho peniano para sua exteriorização. 


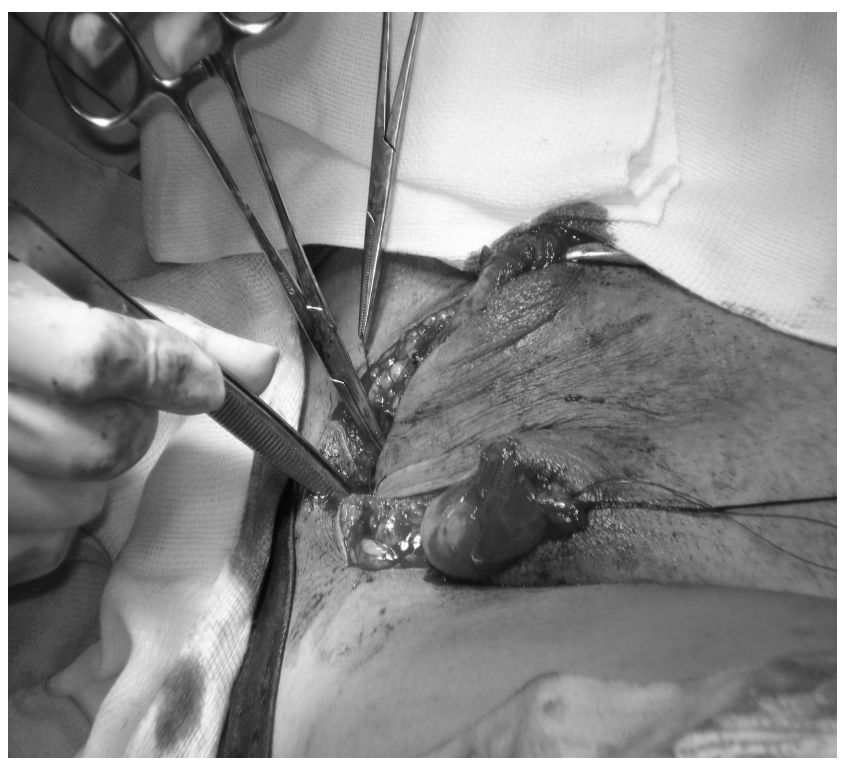

Figura 3-C - O retalho tubular foi introduzido no túnel, com o auxílio de duas pinças, e será fixado no fundo por meio de dois pontos previamente preparados.

Paradoxalmente, é mais fácil construir uma genitália externa de características femininas durante a cirurgia de transgenitalização do que reconstruí-la em malformações ou doenças de pacientes do sexo feminino. A grande quantidade de tecido remanescente após o esvaziamento peniano e escrotal oferece excelentes condições para a construção de vagina e vulva, o que não ocorre em mulheres com alterações genitais.

A técnica tem alguns tempos padronizados que não oferecem maiores dificuldades em sua execução e outros inteiramente dependentes das condições locais e da criatividade do cirurgião.

A retirada dos corpos cavernosos e dos testículos não apresenta grandes dificuldades técnicas pois os planos de clivagem são nítidos. A confecção do túnel no espaço reto-vesical exige maior destreza e experiência do cirurgião, cuja pratica advém da prostatectomia radical por via perineal. A sutura dos retalhos peniano e perineal para formar a neo-vagina implica em avaliar adequadamente seu comprimento e sua largura para que atinja dimensões anatômicas e funcionais. O comprimento ficará sempre na dependência da altura em que se localiza a próstata cuja retirada não recomendamos, pois aumenta a morbidade e impede a fixação adequada do fundo da neovagina. É curioso observar a fantasia das pacientes em relação à profundidade da vagina normal, que sabemos oscilar entre 8 e $10 \mathrm{~cm}$, mas que algumas mencionaram esperar que fosse de 16 e até $24 \mathrm{~cm}$. A queixa de uma profundidade inadequada à expectativa da paciente é freqüente. Este aspecto deve ser abordado no pré-operatório para evitar transtornos, tanto emocional como funcional, no período pós-operatório.

O encurtamento da uretra deve ser suficiente para que não persista uma projeção que se assemelhe a

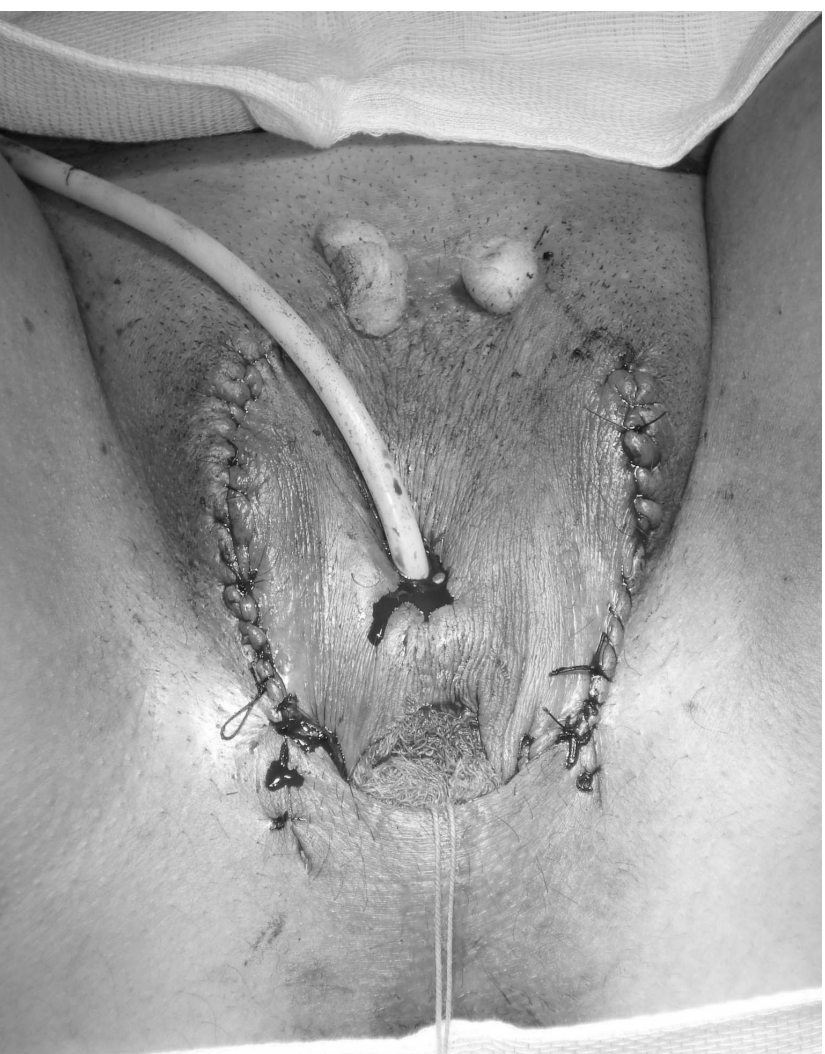

Figura 3-D - Aspecto ao final da operação.

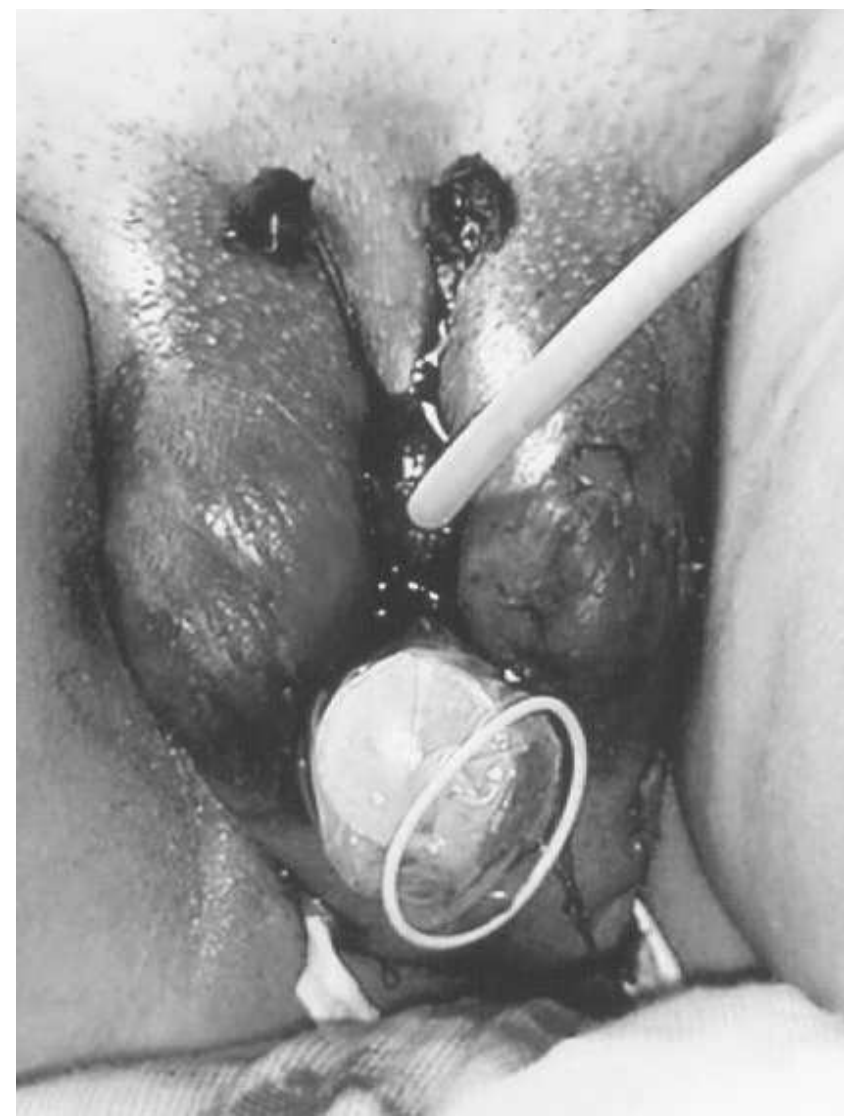

Figura 3-E - Edema acentuado evidenciado no $1^{\circ}$ dia de pósoperatório. 
um pênis residual, mas não tanto que prejudique as adequadas cicatrização e micção. Em uma paciente, foi necessária nova operação para maior encurtamento da uretra. Como mencionamos anteriormente, a uretra mais curta provoca uma depressão na linha média e faz com que os tecidos em seu contorno se assemelhem a pequenos lábios.

Nossa casuística é muito pequena para que possamos discutir complicações tardias. Edgerton ${ }^{1}$ diz, com razão, que "somente um estudo randômico de pacientes acompanhados durante 10 a 20 anos poderia avaliar se este procedimento cirúrgico atendeu as necessidades dos pacientes transexuais".

Casuísticas maiores ${ }^{9}$ relatam como complicações tardias mais freqüentes a estenose da neo-vagina ou do meato uretral e o crescimento de pelos no canal vaginal. A estenose do neo meato uretral é prevista, mas ocorre em menor escala quando na pele é feita uma exérese circular para o implante da uretra. Uma paciente apresentou estenose do neo meato, cuja correção, a meatotomia às seis horas, foi feita no ambulatório, sob anestesia local , no segundo mês do pós operatório.

Fang et al. ${ }^{10}$ lembram que o ângulo sub-púbico masculino é mais fechado do que o feminino e que a neovagina será naturalmente comprimida pelo púbis. Distúrbios psiquiátricos são possíveis em todas as fases pré e pós-operatórias e os pacientes devem ser monitorados de perto durante longo tempo ${ }^{11}$.

O acompanhamento psicológico pós-operatório deve auxiliar na adaptação das pacientes a suas novas condições. O relacionamento, anterior à operação, com um parceiro que concordou com a intervenção, pode terminar ou se alterar. A passagem da relação anal, rotineira, satisfatória e mais fácil, para uma vagina sem umidade e cujo eixo não é exatamente igual ao de uma mulher normal, não se faz sem dificuldade. Acresce o fato de que uma mudança tão radical, mesmo com o apoio pré-operatório do parceiro, pode perturbar o delicado equilíbrio de que são feitas as relações afetivas. É comum o fim do relacionamento ou a persistência da relação anal com uso esporádico da relação vaginal. Em uma de nossas pacientes configurou-se o impasse: o parceiro não conseguia ereção se a relação fosse vaginal e ela não aceitava mais a relação anal. Nenhuma das pacientes em que este desacerto conjugal ocorreu, lamentou ou arrependeu-se de submeter-se a esta operação. Por outro lado, algumas pacientes não tinham nem nunca tiveram parceiro o que confirma a idéia de que a busca pela cirurgia de transgenitalização é muito mais de uma questão ligada à identidade pessoal do que relativa à atividade sexual.

Algumas pacientes, com a finalidade de acentuar o aspecto feminino, podem solicitar a inclusão de próteses mamárias, como rinoplastia, lipoaspiração e diminuição da projeção da cartilagem tireóide, no entanto estas operações só poderão ser realizadas alguns meses após a transgenitalização.

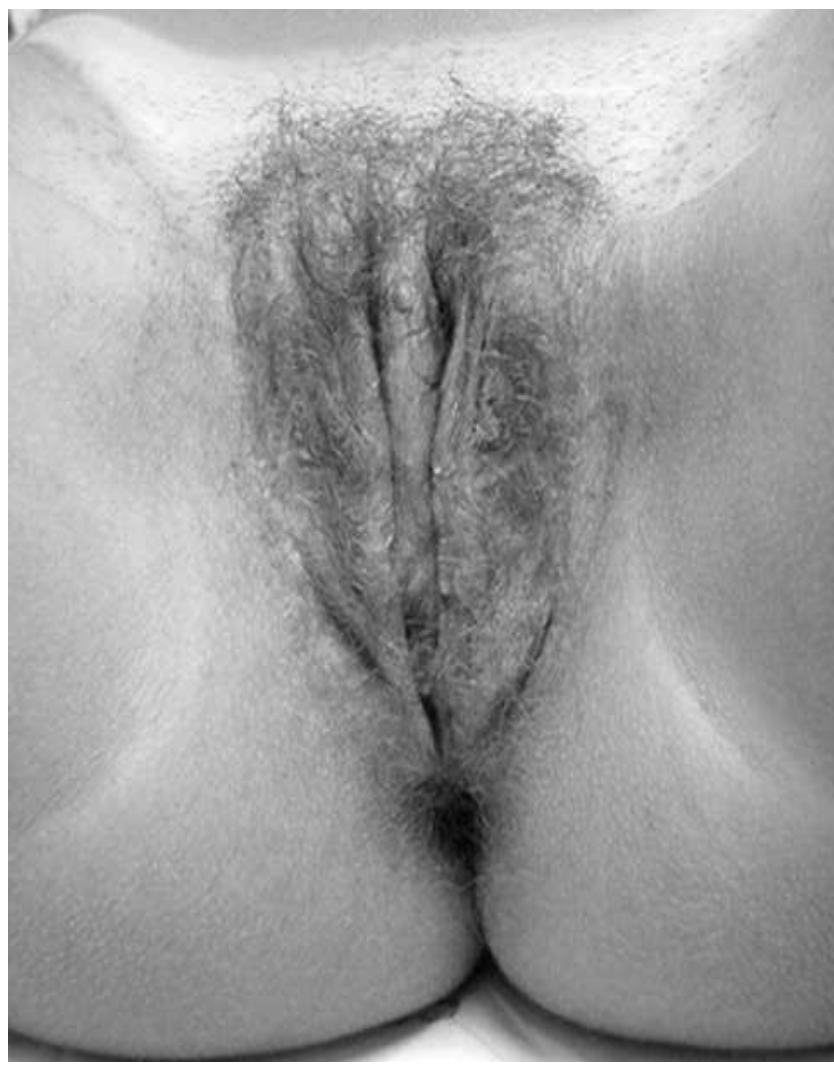

Figura 4-A - Pós-operatório de 5 anos.

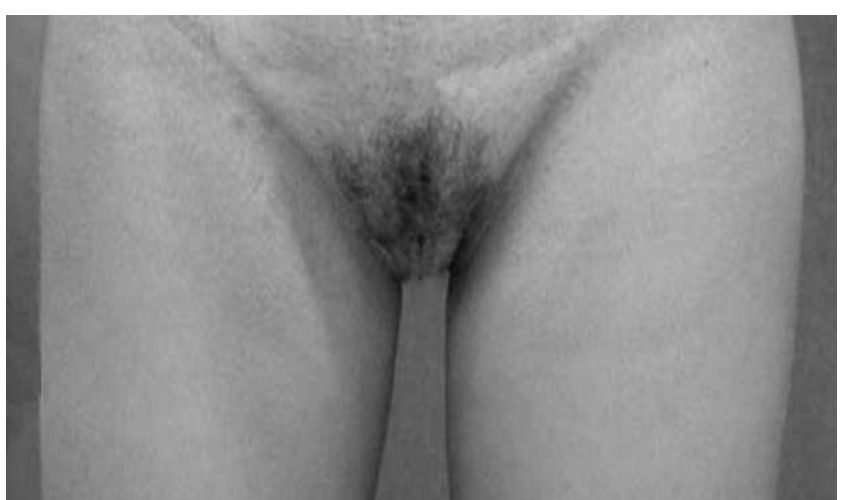

Figura 4-B - Aspecto em posição ortostática.

O fenótipo das pacientes vai se tornando progressivamente mais feminino, com outra maneira de andar, novo corte de cabelo e vestes mais sensuais. É importante que sejam orientadas para evitar os excessos. Exagerar em trejeitos supostamente femininos mas que, na realidade, as mulheres não usam, faz efeito contrário. A nova pessoa que surge após a transgenitalização, não precisa nem deve mostrar-se mais feminina do que mulheres normais. Alguns resquícios de masculinidade, como vestígios de barba, mãos e pés grandes e voz grossa acentuarão o contraste frente a gestos estereotipados.

O acompanhamento endocrinológico destes pacientes é de grande importância, sobretudo porque 


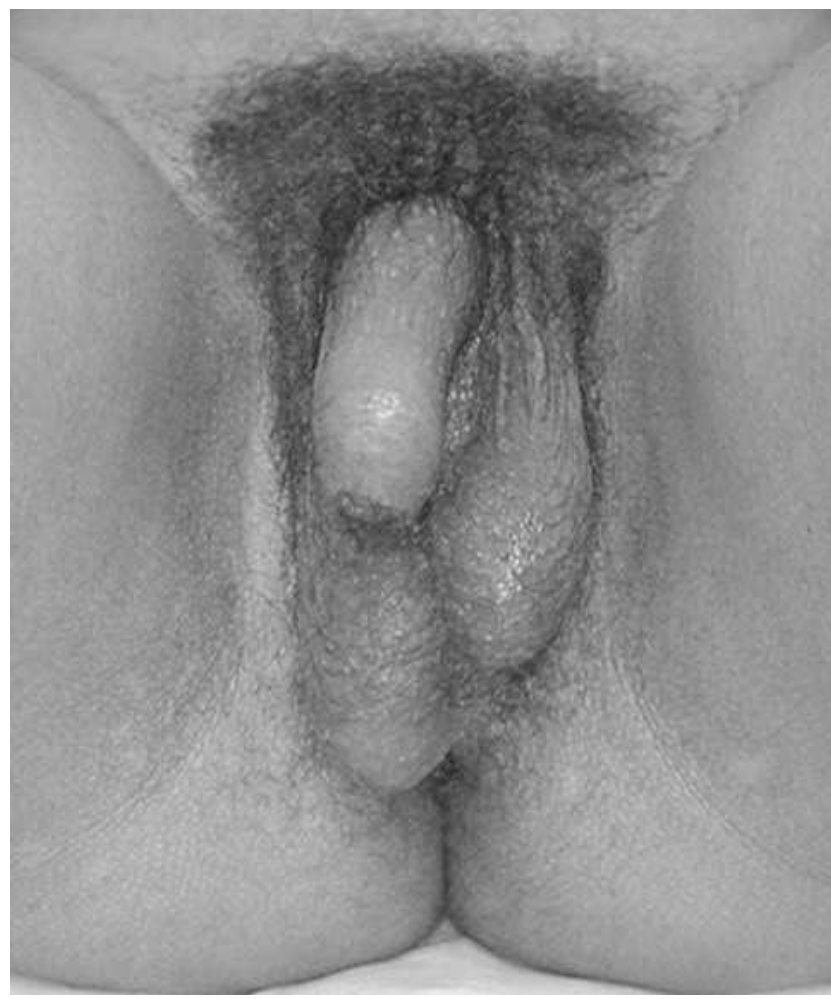

Figura 5-A - Pré-operatório.

a maioria costuma usar estrogênio durante anos, sem controle médico. Asscheman et al. ${ }^{12}$ relataram episódios de tromboembolismo em até $12 \%$ dos pacientes, acima de 40 anos, que se submeteram à transgenitalização. A hiperprolactinemia é um achado comum embora os prolactinomas sejam raros. Moore et al ${ }^{13}$ recomendam a realização da densitometria periódica para controle da massa óssea após castração cirúrgica embora o uso de estrogênio compense a privação da testosterona.

Um aspecto que deve ser também discutido com os pacientes é a perda definitiva da fertilidade e o eventual recurso de armazenar esperma congelado antes da terapia hormonal e do tratamento cirúrgico.

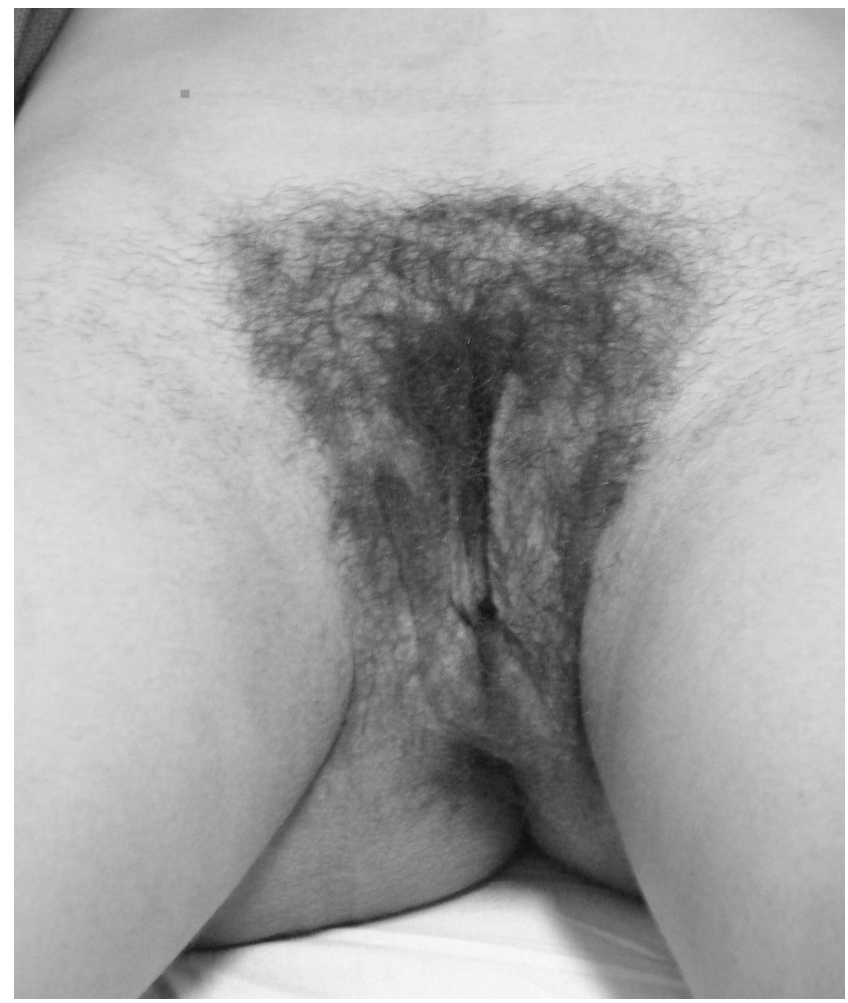

Figura 5-B - Pós-operatório 18 meses.

Um efeito psicológico muito interessante ocorre quando encaminhamos as pacientes para ginecologista com a finalidade de orientá-las em relação a métodos de lubrificação vaginal e para controle das mamas que podem ter recebido doses elevadas de estrogênio ou injeções de silicone feitas por leigos. Este é o momento de seu reconhecimento efetivo como mulher e proporciona satisfação tão grande quanto à colocação de próteses mamárias e, menor apenas, do que a do momento em que a documentação de identidade e o novo nome são registrados. No ano de 2009 retomamos as operações, após longo intervalo de tempo , devido as prioridades assumidas pelas novas necessidades do nosso Hospital. Não incluímos os casos pelo curto período de observação, porém devemos seguir incrementando a nossa casuística.

\section{A $B$ S T R A C T}

Objective: To describe the experience of male-to-female sex reassignment surgery conducted at the Transgenitalization Program of the Clementino Fraga Filho University Hospital -UFRJ. Methods: The selection of patients for operation followed the evaluation of a multidisciplinary team, meeting the criteria after two years of follow-up: medical diagnosis of transsexualism, patient over 21 years, no physical characteristics unsuitable for change, support at least one close relative. Results: From 1997 to 2004 seventeen patients were followed, fifteen of which had confirmed transsexual condition, one was dismissed for bringing false examinations. Of the total of sixteen transsexuals, six operations were performed. The operated patients were in the age range of 25 to 40 years with an average of 31. The surgical procedure was completed without any technical difficulties in all patients. One patient had stenosis of the neo meatus and in another it was necessary to shorten the urethra. Conclusion: The technique provides no major difficulties in implementation, but may depend on local conditions and surgeon's creativity. The greatest difficulty is to prepare these patients so that there are neither frustrations, nor too many expectations.

Key words: Transsexualism/surgery. Transsexualism/diagnosis 


\section{REFERENCIAS}

1. Resolução n. ${ }^{\circ} 482 / 97$ do Conselho Federal de Medicina, publicada no D.O.U. de 19 de setembro de 1997, p. 20.944, Brasília.

2. Resolução $n^{\circ}$. 1652/02 do Conselho Federal de Medicina, publicada no D.O.U. de 06 de novembro de 2002, Brasília.

3. American Psychiatric Association. Diagnosis and statistical manual of mental disorders. $4^{\text {the }}$ edition. Washington DC: American Psychiatric Association; 2000.

4. Young $\mathrm{HH}$. The early diagnosis and radical cure of carcinoma of the prostate: being a study of 40 cases and presentation of a radical operation which was carried out in four cases. Bull John Hopkins Hosp. 1905; 16:315-22

5. Belt E. Radical perineal prostatectomy in early carcinoma of the prostate. J Urol. 1942;48(2):287-97.

6. Edgerton MT, Bull J. Surgical construction of the vagina and labia in male transsexuals. Plast Reconstr Surg. 1970;46(6):529-39.

7. Huang TT. Twenty years of experience in managing gender dysphoric patients: I. Surgical management of male transsexuals. Plast Reconstr Surg. 1995;96(4):921-30; discussion 931-4

8. Fang $\mathrm{RH}, \mathrm{Chen} \mathrm{TJ}, \mathrm{Chen} \mathrm{TH}$. Anatomic study of vaginal width in male-to-female transsexual surgery. Plast Reconstr Surg. 2003;112(2):511-4.

9. Wolf SR, Knorr NJ, Hoopes JE, Meyer E. Psychiatric aspects of transsexual surgery management. J Nerv Ment Dis. 1968;147(5):525-31.
10. Benjamin $H$. The transsexual phenomenon. IJT Electronic Books: Symposion Publishing; 1953. Available from: www.symposion.com/ ijt/benjamin/index.htm

11. Farina R. Transexualismo: do homem à mulher normal dos estados de intersexualidade e das parafilias. São Paulo: Novolunar; 1982.

12. Asscheman H, Gooren LJG, Eklund PL. Mortality and morbidity in transsexual patients with cross-gender hormone treatment. Metabolism. 1989;38(9):869-73.

13. Moore E, Wiesniewiski A, Dobs A. Endocrine treatment of transsexual people: a review of treatment regimens, outcomes, and adverse effects. J Clin Endocrinol Metab. 2003;88(8):3467-73.

Recebido em 21/09/2009

Aceito para publicação em 19/12/2009

Conflito de interesse: nenhum

Fonte de financiamento: nenhuma

\section{Como citar este artigo:}

Franco T, Miranda LC, Franco D, Zaidhaft S, Aran M. Transgenitalização masculino / feminino: experiência do hospital universitário da UFRJ. Rev Col Bras Cir. [periódico na Internet] 2010; 37(6). Disponível em URL: http://www.scielo.br/rcbc

\section{Endereço para correspondência:}

Dra. Talita Franco

E-mail: talita@openlink.com.br 